\title{
Vacuum Erection Device
}

National Cancer Institute

\section{Source}

National Cancer Institute. Vacuum Erection Device. NCI Thesaurus. Code C107636.

Device consisting of a plastic cylinder with an elastic retention band at its base attached to an external pump. The pump creates a vacuum that draws blood into the shaft of the penis and then the user slides the elastic ring down to the base to maintain the erection. 